\title{
Myocardial disorders in a Jamaican rural community
}

\author{
W. E. Miall*
}

WHERE myocardial disease is dominated by the consequences of coronary atheroma it is probable that ill-understood disorders are often wrongly attributed to coronary heart disease. In populations where hypertension is common but occlusive coronary disease is rare, similar conditions are likely to be attributed to hypertension. In this communication I want to illustrate from epidemiological observations in Jamaica, that in a population where hypertension, coronary artery disease, small vessel disease and unexplained cardiomegaly are encountered and myocardial disorders are common there is a very real problem in determining the relative contributions of each.

The International Atherosclerosis Project reported Jamaicans have lower rates for coronary stenosis and coronary atheroma than those for Americans of similar ethnic origin and much lower rates than are found in Europeans or North American whites (McGill et al., 1968). These observations accord with clinical opinion in Jamaica where it is generally accepted that occlusive coronary artery disease is not usually severe and myocardial infarction in particular is relatively rare.

A study of hypertension and heart disease is at present being carried out by the Medical Research Council's Epidemiology Unit in Jamaica (Miall et al., 1972a). An inland rural community from a hilly agricultural district at Lawrence Tavern was selected as representative of many similar populations in the island. The majority were smallholders and they and their families were of predominantly African origin, mostly with Afro-European mixed ancestry. Twelve hundred people, 200 of each sex in the three decades 35-64 were selected at random from the population census of $1962 / 63$. A follow-up survey 5 years after the study started was undertaken in $1967 / 68$. The response-rates in the original survey and the age distribution of the eighty-one deaths which occurred in the 7-8 years of follow-up to September 1970 are shown in Table 1.

The prevalence of, and inter-relationships between hypertension, effort pain and electrocardiographic abnormalities compatible with myocardial ischaemia are shown in Fig. 1 where the area of each rectangle is proportional to the number of subjects involved.

*Present address and address for reprints: MRC/DHSS Epidemiology and Medical Care Unit, Northwick Park Hospital, Watford Road, Harrow, Middlesex, HA1 3UJ.
TABle 1. Populations, response-rates and deaths, Lawrence Tavern, Jamaica

\begin{tabular}{|c|c|c|c|c|c|}
\hline & \multirow[b]{2}{*}{ Age } & \multirow{2}{*}{$\frac{\begin{array}{c}\text { Random } \\
\text { samples }\end{array}}{\text { No. }}$} & \multicolumn{2}{|c|}{ Examined } & \multirow{2}{*}{$\begin{array}{c}\begin{array}{c}\text { Died } \\
\text { before } \\
1 \text { Sept. '70 }\end{array} \\
\text { No. }\end{array}$} \\
\hline & & & No. & $\%$ & \\
\hline \multirow[t]{2}{*}{ Male } & $\begin{array}{l}35-44 \\
45-54 \\
55-64\end{array}$ & $\begin{array}{l}200 \\
200 \\
200\end{array}$ & $\begin{array}{l}168 \\
180 \\
178\end{array}$ & $\begin{array}{l}84 \\
90 \\
89\end{array}$ & $\begin{array}{r}5 \\
13 \\
32\end{array}$ \\
\hline & Total & 600 & 526 & 88 & 50 \\
\hline \multirow[t]{2}{*}{ Female } & $\begin{array}{l}35-44 \\
45-54 \\
55-64\end{array}$ & $\begin{array}{l}200 \\
200 \\
200\end{array}$ & $\begin{array}{l}181 \\
181 \\
179\end{array}$ & $\begin{array}{l}91 \\
91 \\
90\end{array}$ & $\begin{array}{r}3 \\
5 \\
23\end{array}$ \\
\hline & Total & 600 & 541 & 90 & 31 \\
\hline
\end{tabular}

Hypertension, defined in terms of the WHO recommended criterion of $160 / 95 \mathrm{mmHg}$, was common, significantly associated with effort pain and with ECG abnormalities, but at most only accounted for half those with ECG evidence of myocardial damage. Myocardial hypertrophy, unexplained in terms of either hypertension or valvular heart disease was found in many of the remaining cases. Effort pain was considered present if the response to the London School of Hygiene (LSH) questionnaire (Rose, 1962) was positive. The symptom was usually mild and was produced by climbing the precipitously steep hillsides; though it lacked the intensity of typical angina its features fully satisfied the LSH criteria and its association with ECG abnormalities was similar to that found with angina in population surveys in the U.S.A. or U.K. Typical histories of classical myocardial infarction were rare; fifteen men and fourteen women described episodes of severe and prolonged chest pain compatible with minor infarctions but these had rarely caused hospitalization. These subjects also showed ECG changes compatible with myocardial ischaemia as frequently as is found in survivors of myocardial infarction in community surveys of Western industrial populations.

ECG abnormalities were defined as compatible with ischaemia if abnormal $\mathrm{Q} / \mathrm{QS}$ patterns, ST segment depression and $T$ wave changes and left bundle branch block were present, using Minnesota Code criteria. The prevalence of major ECG abnormalities is compared for men aged 40-49 with that in Framingham (Massachusetts) and Tecumseh (Michigan) in Fig. 2. The rates for $\mathrm{Q} / \mathrm{QS}$ items and left axis deviation were surprisingly similar in the 


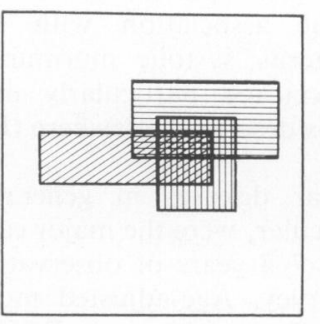

$35-44$
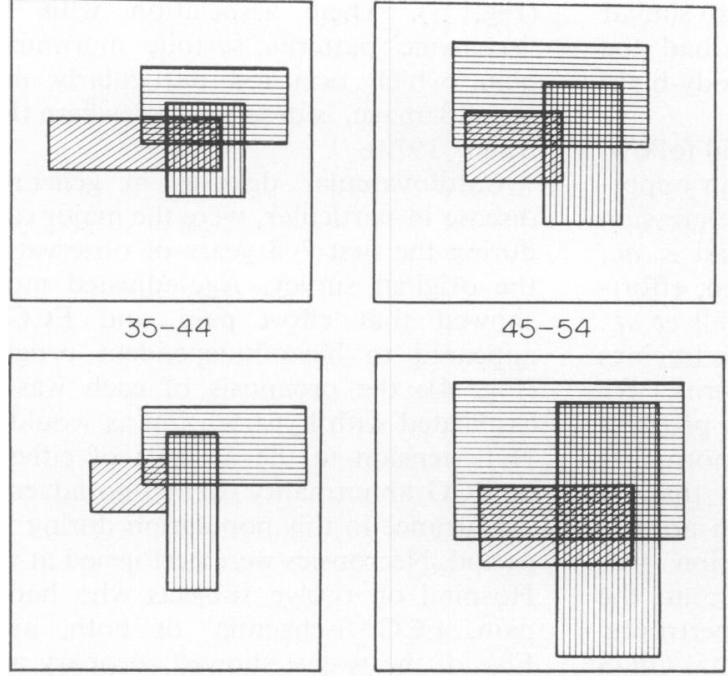

$45-54$

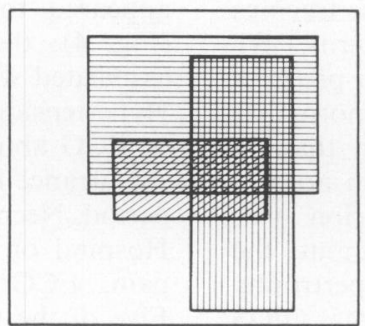

Q Female

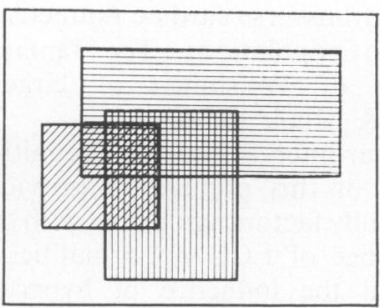

$55-64$

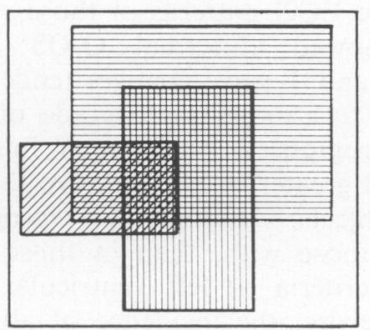

FIG. 1. The inter-relationship between hypertension (horizontal hatching), effort pain (diagonal hatching) and ECG 'ischaemia' (vertical hatching) by age and sex. The areas are proportional to the number of subjects with each characteristic. Open areas represent normal tension

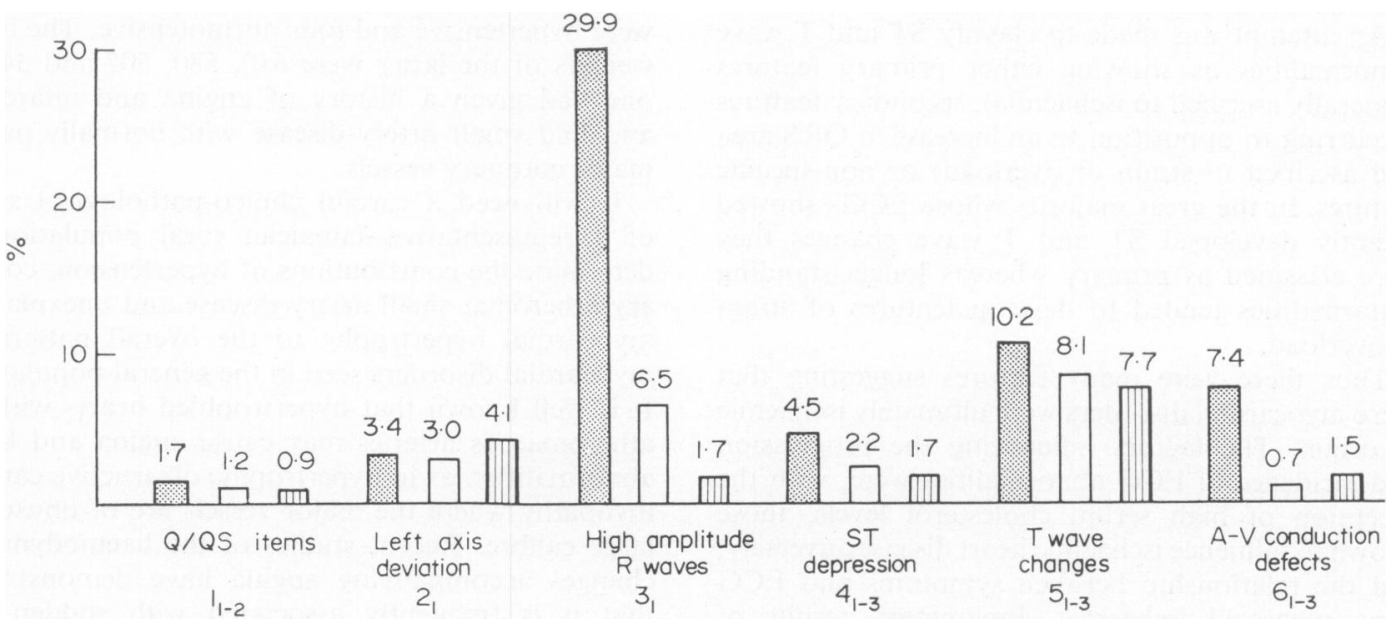

FIG. 2. A comparison of the prevalence of major ECG abnormalities in males aged 40-49. Stippled columns, Lawrence Tavern, Jamaica; open columns, Framingham, Mass. (Higgins et al., 1965); vertically hatched columns, Tecumseh, Michigan (Ostrander, 1966).

three populations, the main distinguishing features being the high prevalences in the Jamaican tracings of large amplitude $\mathbf{R}$ waves in left ventricular leads, the higher rates for $S T$ depression and $T$ wave changes and for atrio-ventricular conduction defects.

Clinical examination suggested that cardiac enlargement was common in this population and frequently associated with functional systolic murmurs which in most cases were attributed to relative mitral incompetence. Organic valvular heart disease was rare. A radiological comparison between the cardiac sizes of these rural Jamaicans and those of an agricultural population in Wales showed that the distributions of cardiothoracic ratios were shifted to 
higher values at each age among Jamaicans but this was largely due to their smaller transverse thoracic diameters; transverse cardiac diameters were similar in the two populations. The Jamaicans had the heart size of Welshmen of larger body-build (Ashcroft \& Miall, 1969).

The 5-year interval between the initial and followup surveys of this population provided an opportunity to study factors associated with the progression and incidence of ECG abnormalities (Miall et al., 1972c) and the influence of hypertension, effortpain and ECG changes on mortality (Miall et al., 1972b). The ECG patterns of those whose tracings initially showed abnormal $\mathrm{Q} / \mathrm{QS}$ patterns, ST depression and $T$ wave changes tended to progress from a less to a more severe grade of abnormality and this progression was greater in men than in women and greater in hypertensive than in normotensive subjects. Among men, progression was greater in those with, than in those without, the amplitude criteria of left ventricular hypertrophy (LVH); likewise, the incidence of abnormal Q/QS patterns among those whose tracings were previously without these features was greater in men than in women. In both sexes the incidence of 'ischaemic' abnormalities was greater in hypertensive than in normotensive subjects. Among men the incidence was again higher in those with LVH.

An attempt was made to classify $S T$ and $T$ wave abnormalities as showing either primary features (generally ascribed to ischaemia), secondary features (occurring in opposition to an increase in QRS area and ascribed to strain or overload) or non-specific features. In the great majority whose ECGs showed recently developed ST and $\mathrm{T}$ wave changes they were classified as primary whereas longer-standing abnormalities tended to develop features of strain or overload.

Thus there were many features suggesting that these myocardial disorders were ultimately ischaemic in origin. The factors influencing the progression and incidence of ECG abnormalities were, with the exception of high serum cholesterol levels, those known to influence ischaemic heart disease adversely, and the relationship between symptoms and ECG signs suggested ischaemia. Preliminary results of tests of cardiopulmonary function, however, including electrocardiography after submaximal exercise, have not revealed the typical changes associated with occlusive coronary artery disease (Miller, 1971), and a study was designed to examine the relationship between LVH and other cardiac abnormalities. Two indices of ECG-LVH, the Sokolow-Lyon criteria (Sokolow \& Lyon, 1949) and Estes' score (Estes, 1966) and one of impaired left atrial activationMorris' Index (Morris et al., 1964) revealed considerably higher prevalences of severe ECG-LVH and left atrial damage in men than in women, despite their lower prevalence of hypertension (Fig. 3). Their association with hypertension, 'ischaemic' patterns, systolic murmurs and effort pain, which occurred particularly in those with atrial damage, is described elsewhere (Ruiz, Miall \& Swan, 1972).

Cardiovascular diseases in general, and heart disease in particular, were the major causes of death during the first 7-8 years of observation following the original survey. Age-adjusted mortality ratios showed that effort pain and ECG 'ischaemia' appeared to have independent prognostic values (Fig. 4); the prognosis of each was worse when associated with hypertension as would be expected. Hypertension in the absence of either effort pain or ECG abnormality carried no adverse prognostic significance in this population during the follow-up period. Necropsies were performed at the University Hospital on twelve subjects who had either effort pain, ECG 'ischaemia' or both, at the survey. Five of the twelve showed coronary atheroma of a severity which could account for the clinical findings; four had obvious myocardial scarring and one of these had severe small vessel disease in addition to occlusive changes in the extramural arteries. Seven of the twelve showed minimal atheroma and little macroscopic evidence of myocardial fibrosis; three were hypertensive and four normotensive. The hearto weights of the latter were $610,580,505$ and $340 \mathrm{~g}$; one had given a history of angina and infarction and had small artery disease with normally patent major coronary vessels.

It will need a careful clinico-pathological study of a representative Jamaican rural population to determine the contributions of hypertension, coronary atheroma, small artery disease and unexplained myocardial hypertrophy to the overall pattern of myocardial disorders seen in the general population. It is well known that hypertrophied hearts without atheromatous arteries may cause angina and ECG abnormalities, as in hypertrophic obstructive cardiomyopathy where the major vessels are of unusually large calibre. Recent studies of the haemodynamic changes accompanying angina have demonstrated that it is frequently associated with sudden left ventricular distention (Parker et al., 1966; 1969; 1970) and that this may be due to other factors than an inadequate arterial supply from major vessels (Fowler et al., 1969; Parker et al., 1969).

If ischaemic processes underlie the pathology of most of the cases of myocardial disorder in this Jamaican population, as is suggested by many of the epidemiological findings, the site of the circulatory deficiency is certainly not always in the extramural coronary vessels. Nor does hypertension appear to be an adequate explanation of the findings. Kannel and 


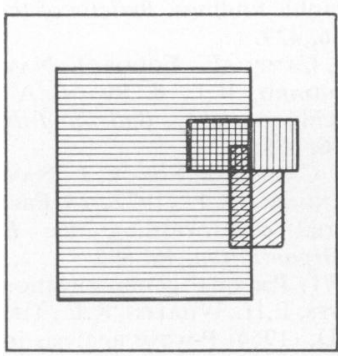

$35-44$
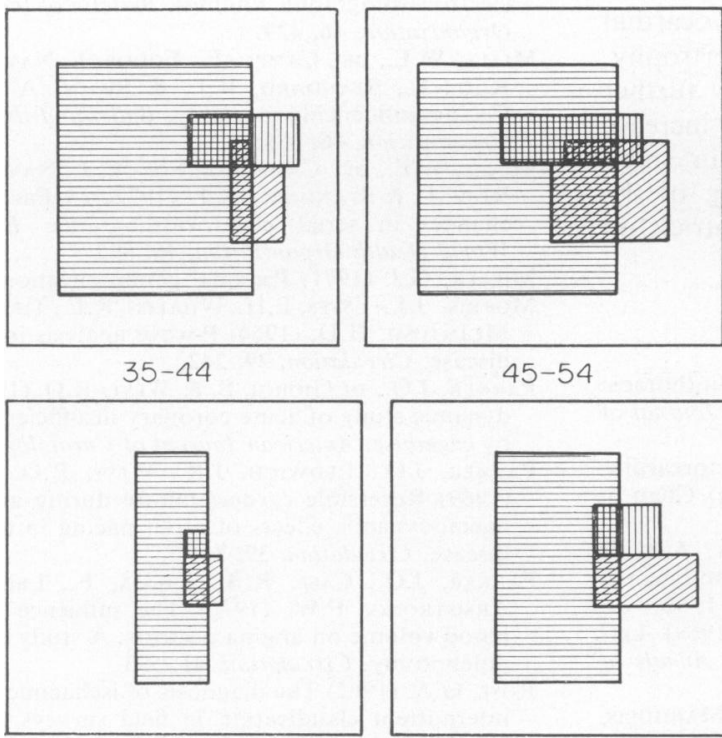

$45-54$

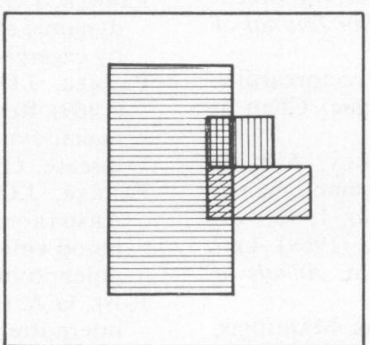

of Female

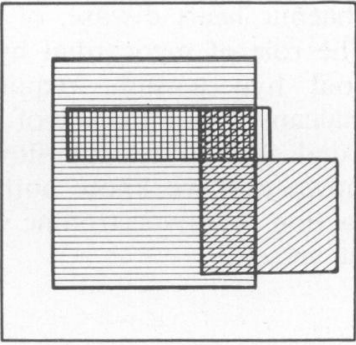

$55-64$

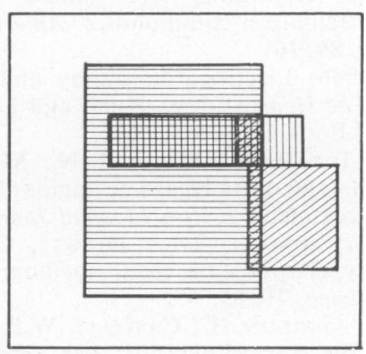
FIG. 3. The inter-relationship between two indices of ECG-LVH and impaired left atrial conduction by age and sex. The areas are proportional to the number of subjects with each
characteristic. Horizontal hatching, mild ECG-LVH(Sokolow-Lyon + ve); vertical hatching, severe ECG-LVH (Estes' score $\geqslant 5$ ); diagonal hatching, impaired left atrial activation (Morris' Index <-0.03); open areas, no ECG-LVH, atrial activation normal.

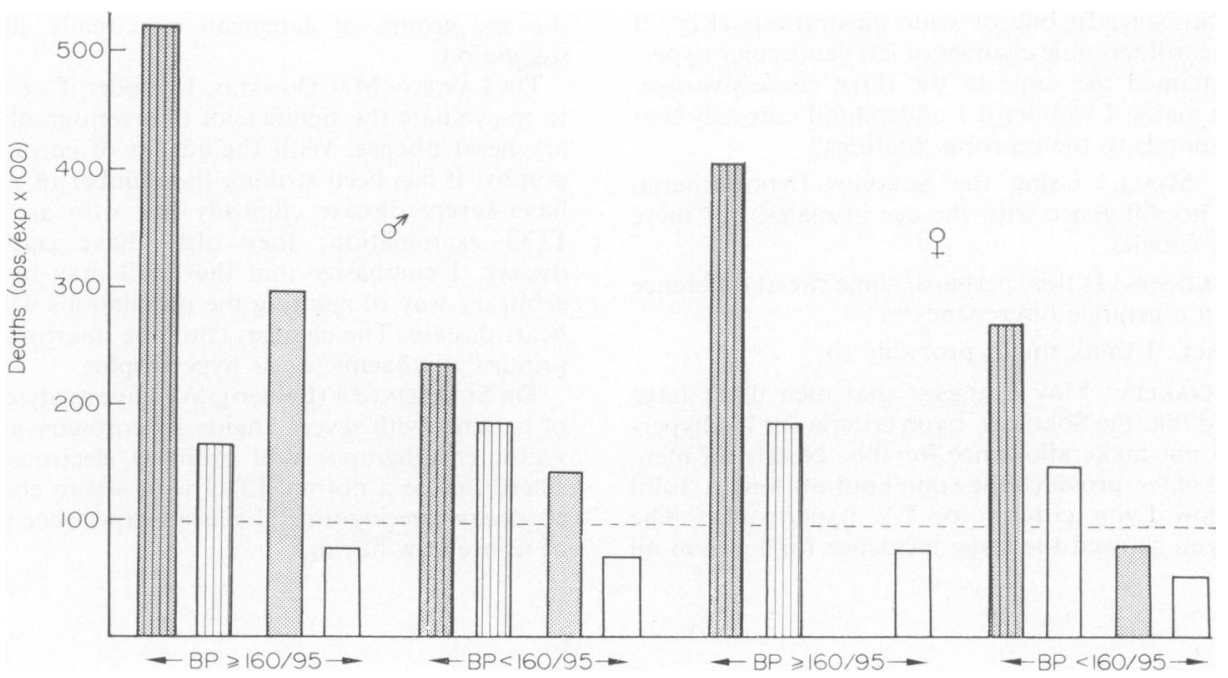

FIG. 4. Age-adjusted mortality ratios according to arterial pressure, effort pain and ECG status at initial survey, Lawrence Tavern, Jamaica. Stippled columns, with angina; vertically hatched columns, with ECG 'ischaemia'; open columns, without angina or 'ischaemia'. 
his colleagues $(1969,1970)$ have reported from Framingham the serious prognostic significance, in terms of ischaemic heart disease, of myocardial hypertrophy. The role of myocardial hypertrophy, with or without hypertension, requires further research in Jamaicans. The influence of an increase in intramyocardial tension on the flow in small vessels is unknown and we know nothing of the effects of contraction of a hypertrophic ventricle on the flow in these vessels.

\section{References}

Ashcroft, M.T. \& Miall, W.E. (1969) Cardiothoracic ratios in two Jamaican communities. American Journal of Epidemiology, 89, 161.

EsTES, E.H. (1966) Electrocardiography and vectorcardiography. In: The Heart (Ed. by Hurst and Logue), Chap. 6. McGraw Hill Book Co., New York.

Fowler, P.B., Ikram, H., Maini, R.N., Makey, A.R. \& KIRKHAM, J.S. (1969) Bradycardiac angina: haemodynamic aspects and treatment. British Medical Journal, 1, 92.

Kannel, W.B., Gordon, T. \& OffutT, D. (1969) Left ventricular hypertrophy by electrocardiogram. Annals of Internal Medicine, 71, 89.

Kannel, W.B., Gordon, T., Castelli, W.P. \& Margolis, J.R. (1970) Electrocardiographic left ventricular hypertrophy and risk of coronary heart disease. Annals of Internal Medicine, 72, 813.

McGill, H.C. et al. (1968) The geographic pathology of atherosclerosis. Laboratory Investigations, 18, 465.

Miall, W.E., del Campo, E., Fodor, J., Nava Rhode, J.R., Ruiz, L., Standard, K.L. \& Swan, A.V. (1972a) A longitudal study of heart disease in a Jamaican rural population. (1) Prevalence data with special references to electrocardiographic findings. Bulletin of the World Health Organization, 46, 429.

Miall, W.E., del Campo, E., Fodor, J., Nava Rhode, J.R., Ruiz, L., Standard, K.L. \& Swan, A.V. (1972b) (2) Factors influencing mortality. Bulletin of the World Health Organization, 46, 685.

Miall, W.E., Del Campo, E., Fodor, J., Nava Rhode, J.R., Ruiz, L. \& STANDARD, K.L. (1972c)(3) Factors influencing changes in serial electrocardiograms. Bulletin of the World Health Organization, 46, 695.

Miller, G.J. (1971) Personal communication.

MorRis, J.J., Estes, E.H., Whalen, R.E., Thompson, H.K.\& McIntosh, H.D. (1964) P-wave analysis in valvular heart disease. Circulation, 29, 242.

Parker, J.O., Di GioRgi, S. \& West, R.O. (1966) A haemodynamic study of acute coronary insufficiency precipitated by excercise. American Journal of Cardiology, 17, 470.

Parker, J.O., Ledwich, J.R., West, R.O. \& CaSe, R.B. $\vec{\infty}$ (1969) Reversible cardiac failure during angina pectoris: haemodynamic effects of atrial pacing in coronary artery disease. Circulation, 39, 745.

Parker, J.O., Case, R.B., Khaja, F., Ledwich, J.R. \& V ARMSTRONG, F.W. (1970) The influence of changes in $\bigcirc$ blood volume on angina pectoris. A study of the effects of 을 phlebotomy. Circulation, 41, 593.

ROSE, G.A. (1962) The diagnosis of ischaemic heart pain and intermittent claudication in field surveys. Bulletin of the World Health Organization, 27, 645.

Ruiz, L., Miall, W.E., and Swan, A.V. (1972) Electrocardiographic indices of left heart involvement in adults a Jamaican rural population. To be published.

Sokolow, M. \& LYON, T.P. (1949) The ventricular comple in left ventricular hypertrophy as obtained by unipolis precordial and limb leads. American Heart Journal, 37, $16 \sigma^{\circ}$ ?

\section{Discussion}

DR DICKINSON: In one of your illustrations (Fig. 2) the electrocardiographic changes of left ventricular hypertrophy remained the same in the three successive agedecades in males. I wonder if I understood correctly that this corresponds to the necropsy findings?

DR W. MIALl: Using the Sokolow-Lyon criteria, there was no difference with the age in males, but there was in the females.

DR DICKInson: Is this, perhaps, some racial difference rather than a genuine discrepancy?

Dr MIALl: I think this is probably so.

DR C. OAKLeY: May I suggest that men don't have breasts and that the Sokolow-Lyon criteria for LV hypertrophy do not make allowance for this. Nearly all men, young and older, provided they don't put on weight, fulfil the Sokolow-Lyon criteria for LV hypertrophy. The fact that you showed the same incidence for LVH in all the age groups of Jamaican men really supports this suggestion.

DR LAWSON MACDONALD: I wonder if we do not have to re-evaluate the significance of arteriography in coronary heart disease. With the advent of coronary arteriography, it has been striking the number of patients who have severe disease clinically but who are normal on ECG examination; they often have cerebrovascular disease. I emphasize that the ECG may be an entirely 3 arbitrary way of splitting the populations with coronary heart disease. The changes could be interpreted either as primarily ischaemic or as hypertrophic.

DR SCHLESINGER (Leiden): We have analysed a number 을 of patients with severe angina by coronary angiography, $D$ vector cardiography and ordinary electrocardiography. There can be a normal ECG with severe changes in the coronary arteriogram. This is an experience which many of of us are now having. 